\title{
Water Treatment by Electrocoagulation, Sorption and Photocatalytic Oxidation
}

\author{
Jana Gaalova, Petr Kluson, Pavel Krystynik and Olga Solcova \\ Institute of Chemical Process Fundamentals of the ASCR, v.v.i., Rozvojova 135, 16500 Prague, \\ Czech Republic
}

\begin{abstract}
Three methods - electrocoagulation, sorption and photocatalytic oxidation - were applied on variety of organic and inorganic compounds in simulated waste waters, but also on real polluted industrial waste waters. Application of the individual technique depends on a type of water contamination.
\end{abstract}

Keywords: water treatment, electrocoagulation, sorption, photocatalytic oxidation

\section{Introduction}

Pollution of water is to be taken seriously since we deal with very important resource for people and the environment. Adjusting of new or existing methods for water purification is crucial to achieve ecologically and economically effective processes. This study focuses on three treatment ways: electrocoagulation, sorption and photocatalytic oxidation. Chosen methods are described in more details in next paragraphs. It is possible to use them separately, or as a part of a combine process. The research emphases their application on variety of organic and inorganic compounds in simulated waste waters, but also on real polluted industrial waste waters.

\section{Research Methods And Main Results}

\subsection{Electrocoagulation}

Electrocoagulation is an electrochemical treatment technology employing DC current to convert metallic aluminium $(\mathrm{Al})$ or iron $(\mathrm{Fe})$ into their ionic species $\mathrm{Al}^{3+}$ and $\mathrm{Fe}^{2+}$ and ${ }^{3+}$ through the controlled corrosion of electrodes.

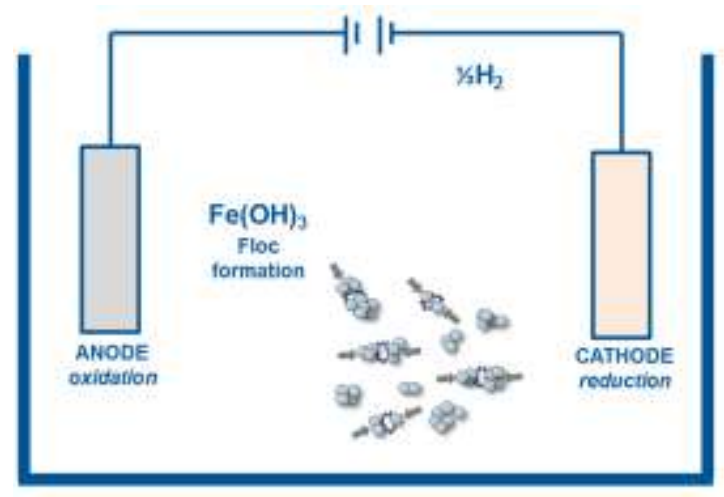

Fig. 1: Floc formation of hydroxide character by electrochemical dissolution of anode. 
In fact, the method utilizes electrochemical dissolution of electrode and simultaneous creation of small hydroxide particles (coagulants) in solutions (Fig. 1). These small particles aggregate to larger particles (flocs) which can be described as highly porous aggregates created from many smaller particles. Flocs comprise oxides, hydroxides and oxohydroxides that reveal high adsorption capacity. Interaction with pollutants and their absorption is one of particular phases of electrocoagulation. Since current flow is required in order to regulate the corrosion rate, a variable potential difference is applied across the electrodes to sustain a constant current. [1]

Main advantages of the process are:

- No chemicals consumption

- Particle aggregates can be easily filtered

- Applied electrical field sets small colloidal particles in faster motion so they can be removed

- Treated water is colorless, clear, palatable and odorless

Electrochemical experiments were performed using coagulation set-up, schematized on Fig. 2. The concentration of $\mathrm{FeCl}_{3} \cdot 6 \mathrm{H}_{2} \mathrm{O}$ was $50 \mathrm{mg} / \mathrm{L}$ and volume of storage tank was equal $50 \mathrm{~L}$.

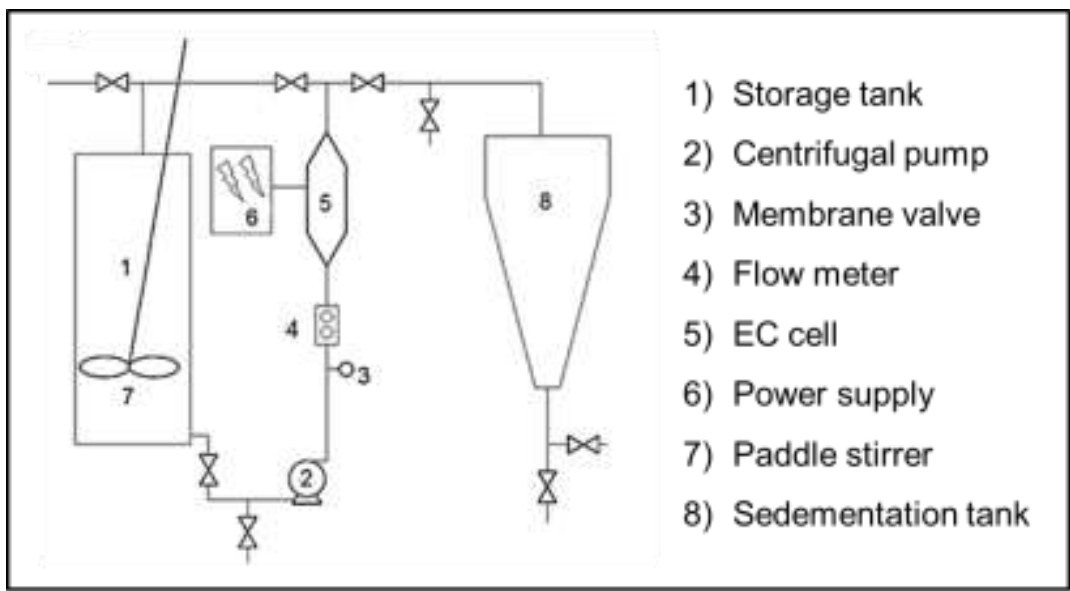

Fig. 2: Electrocoagulation set-up

The main results of water treatment by electrocoagulation method are gathered to the graph of Fe removal efficiency $(\%)$ in a function of current density $\left(\mathrm{mA} / \mathrm{cm}^{2}\right)$, which is the limiting factor of the process (Fig. 3). Fe removal efficiency reached up to $99 \%$ and total organic carbon removal values were up to $30 \%$.

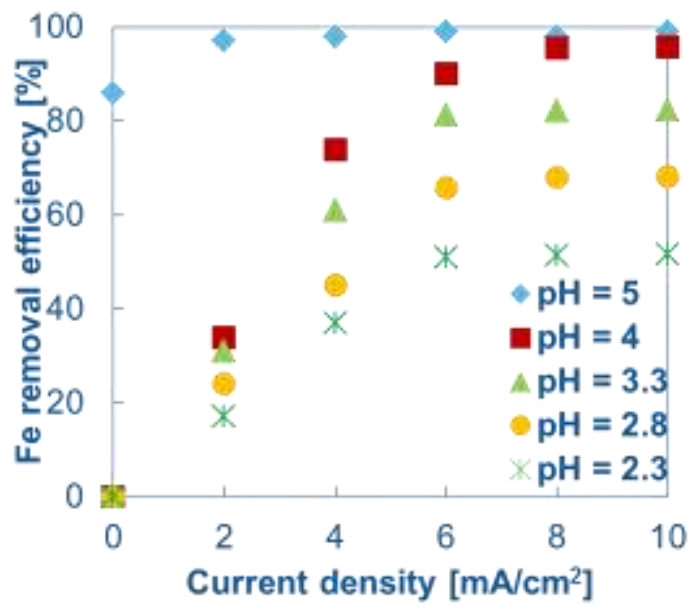

Fig. 3: Fe removal efficiency $(\%)$ in a function of Current density $\left(\mathrm{mA} / \mathrm{cm}^{2}\right)$ 


\subsection{Sorption}

Sorption methods are applicable for variety of contaminants, e.g. heavy metals as well as phenolic compounds which can be found in waste water generated from petroleum and petrochemical, pharmaceutical, plastic, rubber proofing, similarly as steel and phenol production industries. As sorbents usually active carbons, zeolites or special soils are applied [2,3].

Content together with composition of contaminants depend on the type of subsoil. Experiments were performed with UCG post-processing water coming from the experimental mine Barbara in Poland. Results of analyses of the water are in the Table I. below:

TABLE I: Analysis if UCG post-processing water coming from the experimental mine Barbara in Poland

\begin{tabular}{lrlr}
\hline $\begin{array}{l}\text { Inorganic } \\
\text { contaminants }\end{array}$ & $\mathrm{mg} / \mathrm{L}$ & $\begin{array}{l}\text { Organic } \\
\text { contaminants }\end{array}$ & $\mu \mathrm{g} / \mathrm{L}$ \\
\hline Total nitrogen & 1440 & Total phenols & 71000 \\
Chlorides & 34500 & Total BTX* & 448 \\
Ammonium & 1800 & Total PAH** & 338 \\
Zinc & 2070 & Total N- & 14900 \\
Iron & 7070 & heterocycles \\
\hline \hline \multicolumn{4}{c}{$*$ BTX - Benzene, toluene, xylene } \\
\end{tabular}

It is clearly seen that chlorides, zinc and iron dominate as the main inorganic compounds. In the group of organic compounds phenols revealed the highest concentration. Thus we focused on their removal by sorption technique from the contaminated water.

Natural zeolites (Bentonite, Montmorillonite) and active carbons (Supersorbon, Norit) were used as sorbents in the laboratory batch experiments and also as a sorption barrier in the pilot flow reactor. They were characterized by Nitrogen physical adsorption, Mercury porosimetry and Helium pycnometry. Their textural properties are summarized in Table II.

TABLE II: Textural properties of sorbents

\begin{tabular}{lrcccccc}
\hline \hline Sample & $\begin{array}{c}\mathrm{S}_{\mathrm{BET}} \\
\left(\mathrm{m}^{2} / \mathrm{g}\right)\end{array}$ & $\mathrm{S}_{\text {meso }}\left(\mathrm{m}^{2} / \mathrm{g}\right)$ & $\begin{array}{c}\mathrm{V}_{\text {micro }}(\mathrm{liq}) \\
\left(\mathrm{mm}^{3} / \mathrm{g}\right)\end{array}$ & $\begin{array}{c}\text { Intrusion volume } \\
\left(\mathrm{cm}^{3} / \mathrm{g}\right)\end{array}$ & $\begin{array}{c}\rho_{\mathrm{He}} \\
\left(\mathrm{g} / \mathrm{m}^{3}\right)\end{array}$ & $\begin{array}{c}\rho_{\mathrm{He}} \\
\left(\mathrm{g} / \mathrm{m}^{3}\right)\end{array}$ & $\begin{array}{c}\varepsilon \\
(-)\end{array}$ \\
\hline Bentonite & 70 & 40 & 15 & 0.26 & 2.41 & 1.32 & 0.46 \\
Supersorbon & 1214 & 442 & 374 & 0.69 & 2.02 & 0.58 & 0.71 \\
Montmorillonite & 471 & 518 & 59 & 1.06 & 2.38 & 0.58 & 0.76 \\
Norit & 731 & 240 & 235 & 1.18 & 2.07 & 0.47 & 0.77 \\
\hline \hline
\end{tabular}

All used sorbents shows good textural properties. They indicate large mesoporous surface, volume of micropores and high porosity. Bentonite is an exception, but it`s usually used for water treatment.

Laboratory batch experiments took place in the shaker. The real waste water from UCG was diluted at volume ratio 1:1 with distilled water. $1 \mathrm{~g}$ of sorbent was used to $100 \mathrm{~mL}$ of the solution. Shaking speed was 200 revolutions per minute and sampling was performed at the beginning, after six hours and after 24 hours of sorption. The pilot flow reactor had moveable arm to enable flow simulation in various column planes. Three parts of the column were present. Two edges parts stabilised the flow through the column and the middle section was filled by different substrates for the various subsoil roughness simulation. The water flow was $6 \mathrm{~L} / \mathrm{h}, 100$ $\mathrm{mL}$ of UCG waste water was injected every 30 minutes and the column retention was $4 \mathrm{~L}$. In both types of sorption treatments were all samples analysed by gas chromatography.

With laboratory scale water treatment, $90 \%$ of sorption efficiency was achieved after $6 \mathrm{~h}$ and almost no residual concentration of phenols was detected after $24 \mathrm{~h}$. The pilot flow reactor gave more than $90 \%$ of sorption efficiency after 4 hours with Norit. After 10 hours, the residual concentration of phenols increased 
nearly to $15 \%$ and remained the same as after $17 \mathrm{~h}$. However, the best results were obtained by using Supersorbon as the sorption barrier. $100 \%$ of sorption efficiency was reached after 3 hours and persisted the same also after $7 \mathrm{~h}$. After 13 hours the efficiency decreased to $85 \%$. It was confirmed that sorbent structure plays an important role. Small particles can flow through sorption barriers; nevertheless, the most important is a sorption capacity of sorbent. Sorption barriers using Norit and Supersorbon are captured on Fig. 4.

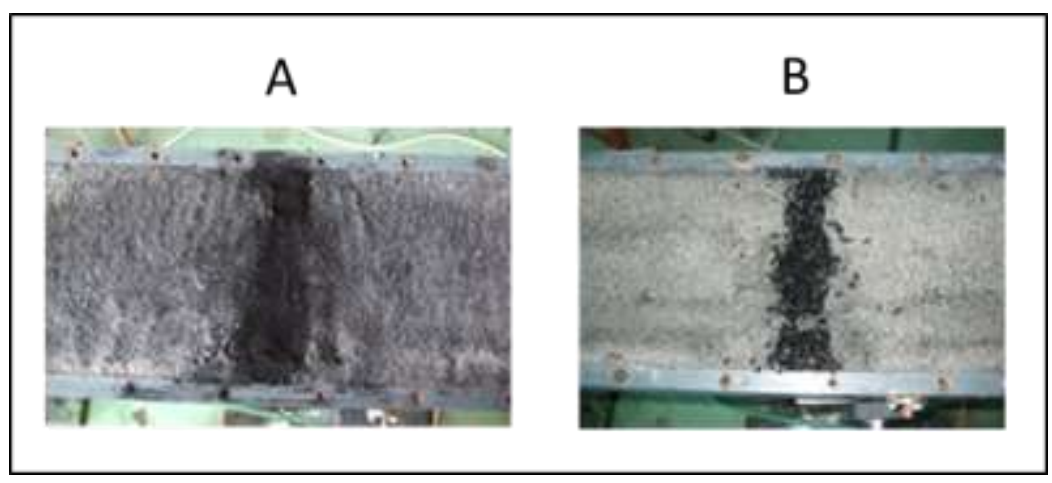

Fig. 4: Sorption barrier using Norit (A) and Supersorbon (B)

\subsection{Photocatalytic Oxidation}

Photocatalysis belongs among Advanced Oxidation Processes (AOPs) and seems to be a really promising technology for degradation of endocrine disrupting compounds (EDCs) [4-6]. Therefore, 17 $\alpha$-ethynylestradiol (EE2) the pharmaceutical substance of hormonal contraception, was chosen for photocatalytic tests. The treatment is based on formation of highly reactive species which can degrade even the most recalcitrant molecules. The most commonly used photocatalyst is titanium dioxide $\left(\mathrm{TiO}_{2}\right)$ which is applied in the form of powder or immobilized in a thin layer [7].

For presented tests, $\mathrm{TiO}_{2}$ was successfully prepared in the form of thin layers coated on glass beads and tubes and it was used as a photocatalyst in the batch reactor and plug flow reactor for photocatalytic degradation of EE2. The design of an AOP is governed by target effluent contaminant concentration, desired flow rate or background water quality parameters such as $\mathrm{pH}$. Reacting conditions for both reactors are resumed in Table III.

TABLE III: Reacting conditions for batch and continuous reactor

\begin{tabular}{lcc}
\hline \hline Parameters & Batch reactor & Continuous reactor \\
\hline Temperature & $26-33{ }^{\circ} \mathrm{C}$ & $26-35^{\circ} \mathrm{C}$ \\
$\mathrm{pH}$ & $5-6$ & $5-6$ \\
Concentration of EE2 & $20-25 \mathrm{ppm}$ & $11-14 \mathrm{ppm}$ \\
Weight of catalyst & $2.5 \mathrm{mg} / 5 \mathrm{~g}$ beads & $2.2 / 4$ tubes \\
& $200 \mathrm{ml}$ of reaction mixture & Tubes length equal \\
Other & Continuous shaking & $10 \mathrm{~cm}$ respectively \\
& during the experiment $(8 \mathrm{~h})$ & \\
\hline \hline
\end{tabular}

Estrogenic activity and toxicity of intermediates were measured during the experiment. The estrogenity was measured by yeast Saccharomyces cerevisiae which are able to produce light after exposure to hormonally active substances. Toxicity was manifested by inhibition of bioluminescence bacteria Vibrio fischeri strain NRLL-B11177 , determined by the manual luminometer. 
The total degradation was achieved in batch reactor after 8 hours. In the plug flow reactor, the residence time was only $32 \mathrm{~min}$. The values of estrogenity decreased proportionally to EE2 concentration and no toxicity was detected during the ethynylestradiol degradation process.

\section{Conclusion}

Electrocoagulation, sorption and photocatalytic oxidation - were applied on variety of organic and inorganic compounds in simulated waste waters, but also on real polluted industrial waste waters. All the treatments proved high efficiency in degradation of pollutants. Limiting factors of each process were pointed out. However, application of individual technique depends on type of water contamination; therefore they were used for different kind of pollutants.

\section{Acknowledgements}

The financial support of TACR project TA04020130 is gratefully acknowledged acknowledge.

\section{References}

[1] D. N. Tito, P. Krystynik and P. Kluson, "Notes on process and data analysis in electro-coagulation-The importance of standardisation and clarity", Chemical Engineering and Processing: Process Intensification, vol. 104, pp. 22-28, June 2016.

https://doi.org/10.1016/j.cep.2016.02.011

[2] A. A. Zaki, M. I. Ahmad and K. M. Abd El-Rahman, "Sorption characteristics of a landfill clay soil as a retardation barrier of some heavy metals", Applied Clay Science, vol. 135, pp. 150-167, January 2017.

https://doi.org/10.1016/j.clay.2016.09.016

[3] K. G. Akpomie, D. Mantzavinosa and D. Kassinosa, "Treatment of an automobile effluent from heavy metals contamination by an eco-friendly montmorillonite", Journal of Advanced Research, vol. 6 (6), pp. 1003-1013, November 2015.

https://doi.org/10.1016/j.jare.2014.12.004

[4] M. Klavariotia, D. Mantzavinosa and D. Kassinosa, "Removal of residual pharmaceuticals from aqueous systems by advanced oxidation processes”, Environment International, vol. 35 (2), pp. 402-417, February 2009.

https://doi.org/10.1016/j.envint.2008.07.009

[5] M. Gmurek, M. Olak-Kucharczyk and S. Ledakowicz, "Photochemical decomposition of endocrine disrupting compounds - A review", Chemical Engineering Journal, vol. 310, pp. 437-456, February 2017. https://doi.org/10.1016/j.cej.2016.05.014

[6] H. Katsumata, S. Kawabe, S. Kaneco, T. Suzuki and K. Ohta, "Degradation of bisphenol A in water by the photoFenton reaction", Journal of Photochemistry and Photobiology A: Chemistry, vol. 162 (2-3), pp. 297-305, March 2004.

[7] Ch. Guo, K. Wang, S. Hou, L. Wan, J. Lv, Y. Zhang, X. Qu, S. Chen and J. Xu, " $\mathrm{H}_{2} \mathrm{O}_{2}$ and/or $\mathrm{TiO}_{2}$ photocatalysis under UV irradiation for the removal of antibiotic resistant bacteria and their antibiotic resistance genes", Journal of Hazardous Materials, vol. 323 (B), pp. 710-718, February 2017. 